\title{
Long-Autonomy Unmanned Aircraft Vehicle (UAV) for Quick Release of Ocean Minidrifters
}

\author{
ANTONIO GómEz RoA \\ Escuela de Ciencias de la Ingeniería y Tecnología, Universidad Autónoma de Baja California, Ensenada, Baja California, Mexico \\ XAVIER FLORES-VIDAL \\ Instituto de Investigaciones Oceanológicas, Universidad Autónoma de Baja California, Ensenada, Baja California, Mexico \\ Orlando Avendaño Gastelum and Rogelio NúÑ̃z \\ Servicios de Diseño e Integración de Sistemas Electrónicos, Tijuana, Baja California, Mexico \\ Andrés Sandoval Rangel and Cesar A. Liera Grijalva \\ Instituto de Investigaciones Oceanológicas, Universidad Autónoma de Baja California, Ensenada, Baja California, Mexico \\ JuAN IVAN NiETO HIPÓLITO \\ Facultad de Ingeniería Arquitectura y Diseño, Universidad Autónoma de Baja California, Ensenada, Baja California, Mexico
}

(Manuscript received 31 October 2019, in final form 2 July 2020)

\begin{abstract}
In this work we present an unmanned aircraft vehicle (UAV) designed from off-the-shelf components to release ocean minidrifters. Its endurance $(\sim 1 \mathrm{~h})$, payload $(\sim 5 \mathrm{~kg})$, offshore range $(\sim 30 \mathrm{~km})$, capability of operating into wind conditions of $\sim 10 \mathrm{kt}\left(1 \mathrm{kt} \approx 0.51 \mathrm{~m} \mathrm{~s}^{-1}\right)$, high-precision autopilot $(2-3 \mathrm{~m})$, and flying altitude of $\sim 500 \mathrm{~m}$ above sea level, along with its relatively low cost $[<\$ 5,000$ (U.S. dollars) ] enables quick and relatively easy oceanographic applications beyond $10 \mathrm{~km}$ offshore. We report here the very first successful ocean drifter releases, performed along the Baja California coast, between Tijuana and Rosarito, Mexico, and the technical details of the UAV. About 50 experiments (flights) allowed us to improve the takeoff and landing, the release tunnel for minidrifters, the cruise speed and altitude to release drifters safely, and to implement a parachute that controls the speed of the freefalling minidrifters. Quick release of up to six drifters (armed with real-time data transfer and web display) between 2 and $12 \mathrm{~km}$ offshore were performed at $\sim 500 \mathrm{~m}$ above sea level, during a single flight in under $15 \mathrm{~min}$, as opposed to classic techniques using boats or ships that, although can transport much more weight, can take several hours, use more human resources, and increase cost. Here we propose a novel opensource technique that can be used as a simplified method for scientific ocean measurements, as a quick-response emergency tool to map spills or for search and rescue.
\end{abstract}

KEYWORDS: Ocean; Trajectories; Aircraft observations; Buoy observations; In situ oceanic observations; Instrumentation/sensors

\section{Introduction}

Ocean transport induced by waves and currents is a widely studied topic in oceanography. Among a long list of physical (e.g., heat) and biological (e.g., productivity) processes that depend on ocean transport, oil spills are one of the most studied processes due to their harmful impact on the environment (e.g., Fingas and Brown 2011; Serra-Sogas et al. 2008). Anthropogenic pressure on coasts is causing various phenomena, not only pollution and oil spill risk, but Sargassum algae blooms that affect the Caribbean and shores of Florida (Hu et al. 2016). Both examples (oil spills and Sargassum blooms) require rapid actions to identify them, predict their trajectories, and mitigate their impact on the environment. Today, there are several methods to measure ocean currents, such as satellite observations (e.g., Dohan and Maximenko 2010; Dohan 2017; among others), high-frequency (HF) radars (Kaplan et al. 2005; Paduan and Washburn 2013), and X-band

Corresponding author: Xavier Flores Vidal, xavier@uabc.edu.mx radars (Díaz Méndez et al. 2015), as well as conventional cruises, which are usually expensive and time consuming. Other methods for monitoring the upper ocean can be performed by manned or unmanned aircrafts using high-resolution photography, lidar, and radiometers (e.g., Reineman et al. 2009). Numerical simulations (e.g., Mateos et al. 2013) offer a good compromise between quick response and relatively low cost. However, they may be limited by the time and amount of human resources needed to adapt them correctly and to validate the results in the study area, thus limiting their rapid response in emergencies. Drifters or Lagrangian programs also provide the opportunity to measure global or regional ocean currents during extended periods of time (e.g., Grodsky et al. 2011; Miron et al. 2019).

Currently, the rapid development of UAVs (De Sousa et al. 2015) allows for a broad range of applications in various disciplines such as geology (Valente et al. 2011), biology (Ventura et al. 2017), and oceanography (Reineman et al. 2016; Klimkowska et al. 2016; Trasviña-Moreno et al. 2017). However, the use of commercial UAVs is limited by their cost, payload, and 
endurance (Skrzypietz 2012), which restricts their longrange applications (beyond $10 \mathrm{~km}$ offshore). Here we present an off-the-shelf, open-source, electric UAV that is specially adapted to release oceanographic instrumentation beyond $10 \mathrm{~km}$ offshore, with improvements to the payload capacity $(5 \mathrm{~kg})$ and autonomy $(\sim 1$-h endurance). The released ocean instrumentation consisted of ocean drifters (equipped with real-time data transmission) to estimate sea surface currents (based on particle trajectories) and sea surface temperatures.

In the following sections, we provide a complete description of the proposed UAV system, its functionalities, hardware, software, and mechanical design. Subsequently, we provide details of the customized minidrifters used and of a series of field experiments. Finally, we make some conclusions and identify areas of opportunities to improve the UAV system.

\section{Off-the-shelf design of the UAV}

Several studies report the use of UAVs to obtain ocean and atmospheric measurements (Reineman et al. 2016), monitor algae blooms (Klimkowska et al. 2016), and identify marine fauna (Verfuss et al. 2019). Autonomy of UAVs is from $30 \mathrm{~min}$ to $7 \mathrm{~h}$ (e.g., Reineman et al. 2016; Skrzypietz 2012), and the spatial range of some can reach up to $100 \mathrm{~km}$. However, they are expensive [ $>\$ 50,000$ (U.S. dollars)] and their autonomy range is proportional to their complexity and payload (Skrzypietz 2012). The payload of most commercial UAVs is $<2 \mathrm{~kg}$, which is sufficient for atmospheric sensors, cameras (visible and infrared), or portable-lidar scanning systems (Reineman et al. 2009). This work presents a customdesigned UAV with a total mass of $\sim 25 \mathrm{~kg}$, a payload capacity of $\sim 5 \mathrm{~kg}$, maximum offshore range of $30 \mathrm{~km}$ (or autonomy of $\sim 1 \mathrm{~h}$ ), low cost of about $\$ 5,000$ (U.S. dollars), and a capacity of transporting and releasing small ocean drifters (buoys) equipped with GPS, temperature sensors, and real-time telemetry modules to track ocean currents and sea surface temperatures. The UAV can be programmed by the user with the flight route and release points for the drifters.

The UAV used for this project was an electric capable fixedwing frame (Mugin 3-m T tail) composed of fiberglass fuselage of $2.5 \mathrm{~m}$ and a wing length of $3 \mathrm{~m}$, with a total mass of $20 \mathrm{~kg}$ including motor, batteries, and electronics (Fig. 1).

The aircraft was equipped with lithium-polymer batteries configured in series-parallel arrays to achieve 50.4-V DC $18000 \mathrm{~mA}$ to provide a flight capacity of up to $1 \mathrm{~h}$ of autonomy with a maximum tested flight of $\sim 30 \mathrm{~km}$ offshore $(60-\mathrm{km}$ round trip) under $<10 \mathrm{kt}\left(1 \mathrm{kt} \approx 0.51 \mathrm{~m} \mathrm{~s}^{-1}\right)$ winds.

The flight computer/autopilot selected was Pixhawk (https:// pixhawk.org/) with the latest PX4 model release, which supports redundant systems like dual GPS modules and dual microelectromechanical system (MEMS) gyroscopes, dual compass (internal and external), two-axis and three-axis accelerometers, and a barometric pressure sensor, among others. This computer provides high precision flight control with two different operating modes: manual and autopilot. The autopilot can be controlled and configured with the use of any Mavlink (https://mavlink.io) compatible ground control software such as Mission Planner (http://ardupilot.org/planner/) or

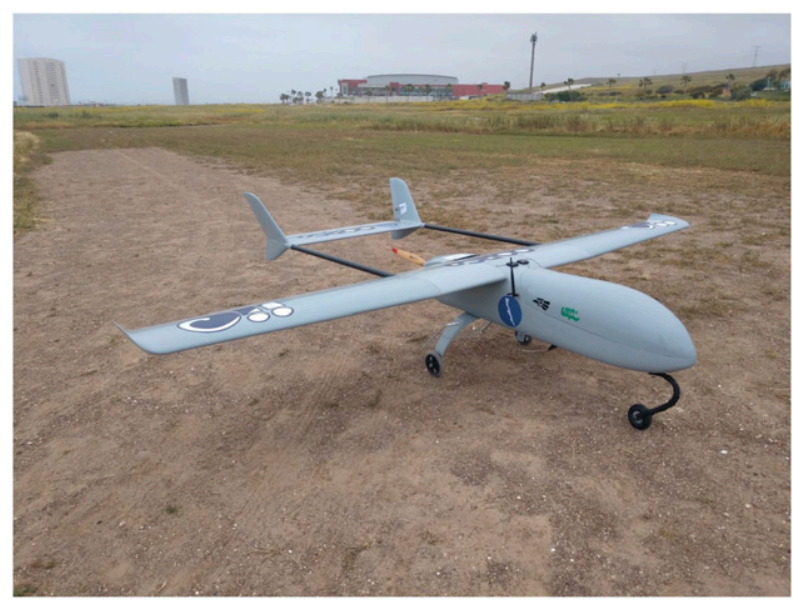

FIG. 1. Customized fixed-wing frame (Mugin 3-m T tail) composed of fiberglass with a wing length of $3 \mathrm{~m}$, and total mass of $20 \mathrm{~kg}$ ( $\sim 5 \mathrm{~kg}$ of payload capacity).

QGround Control (http://qgroundcontrol.com/). This software is a graphical interface which provides real-time data flow of several flight parameters and a georeferenced map for navigation. The implementation of this autopilot achieves an efficient and reliable autonomy. This open electronic platform (open source) consists of flexible software and hardware that can be modified and adapted to suit the needs of the user.

The platform allows missions to be uploaded and configured through a setup of "waypoints," which creates a flight path followed automatically by the UAV while the flight instruments provide the real-time logs. In addition, other flight parameters, such as battery voltage (power), height, speed, wind speed and position logs (tracking), are provided during the entire flight (Fig. 2).

The success of the autopilot relies on a ground control station, which is required to monitor the flight in real time and take action or make corrections when needed. The ground control station has two functions. The first is to upload the parameters that are programmed in the flight computer, such as altitude, speed, latitude, and longitude (path), and the release points for ocean drifters, which are necessary to define the mission. Figure 3 shows an example of a $30-\mathrm{km}$ mission that was set up before the flight; this flight was performed with a cruise speed of $\sim 80 \mathrm{~km} \mathrm{~h}^{-1}$. The second function of the ground control station is to monitor the UAV during the mission. Parameters such as, voltage, battery current, altitude, stability of the aircraft, speed, and the tracking of the route are transferred in real time to the ground station. Therefore, the ground station must then keep a very robust telemetry link with the UAV during the entire flight.

After numerous tests in the laboratory and field experiments, the telemetry system was chosen to avoid interference from the other control devices (e.g., autopilot, accelerometers, voltage regulators, batteries). The telemetry system chosen was a UHF link RFD900 Radio Modem, which supports up to 50 hopping channels in the $900-\mathrm{MHz}$ industrial, scientific, medical (ISM) band and has a dynamic power control between 


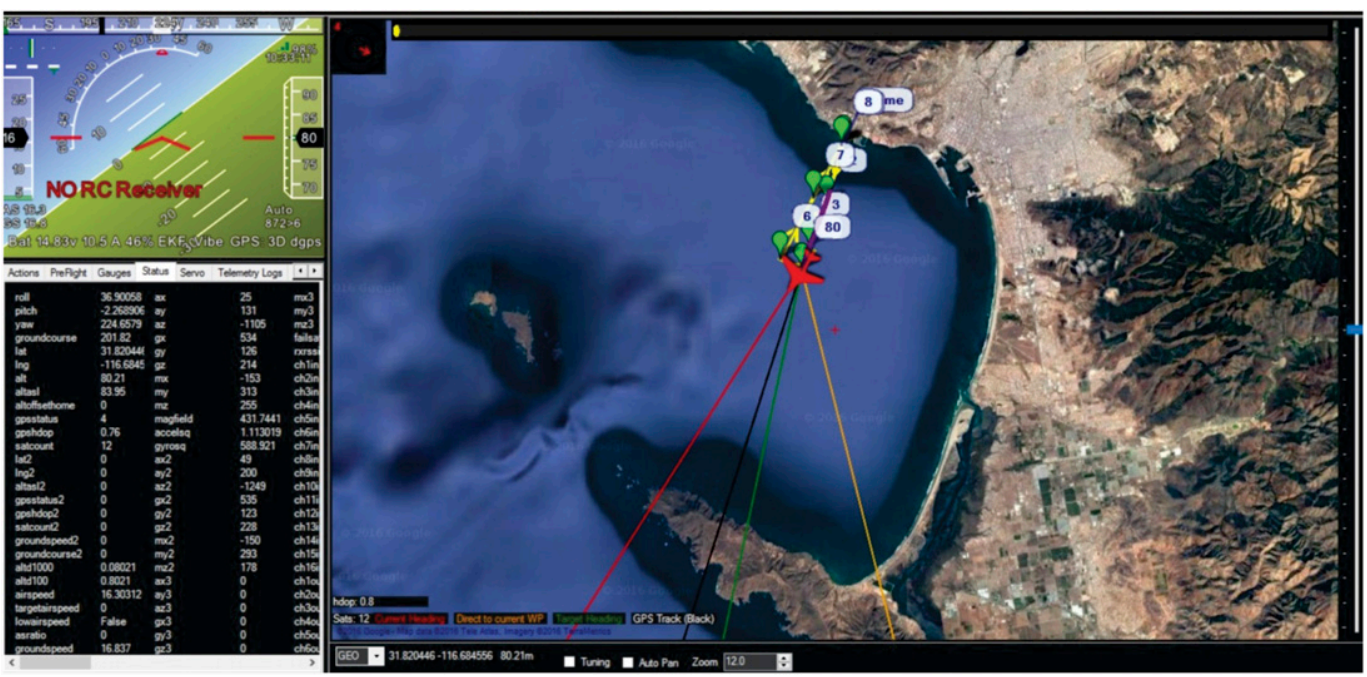

FIG. 2. Graphic interface for configuration and real-time log of the UAV. (bottom left) The real-time data from flight sensors. (top left) The level, gyrocompass, and inclination sensor. (right) Map view showing the real-time position of the UAV (red plane), and preprogrammed positions to release minidrifters (green marks).

100 and $1000 \mathrm{~mW}$; therefore, the transmission power can be reduced to save power and reduce noise (depending on the length of the link). The most important characteristic is that the modem can implement a point-to-point type topology using the Hayes AT commands or using a graphical user interface
(GUI) to change the parameters of the RFD900 modem during the flight, which gives the user the capacity to recover communication if the link is lost during a mission.

The use of the off-the-shelf and open-source tools presented here, greatly reduced operational costs and adaptation times,

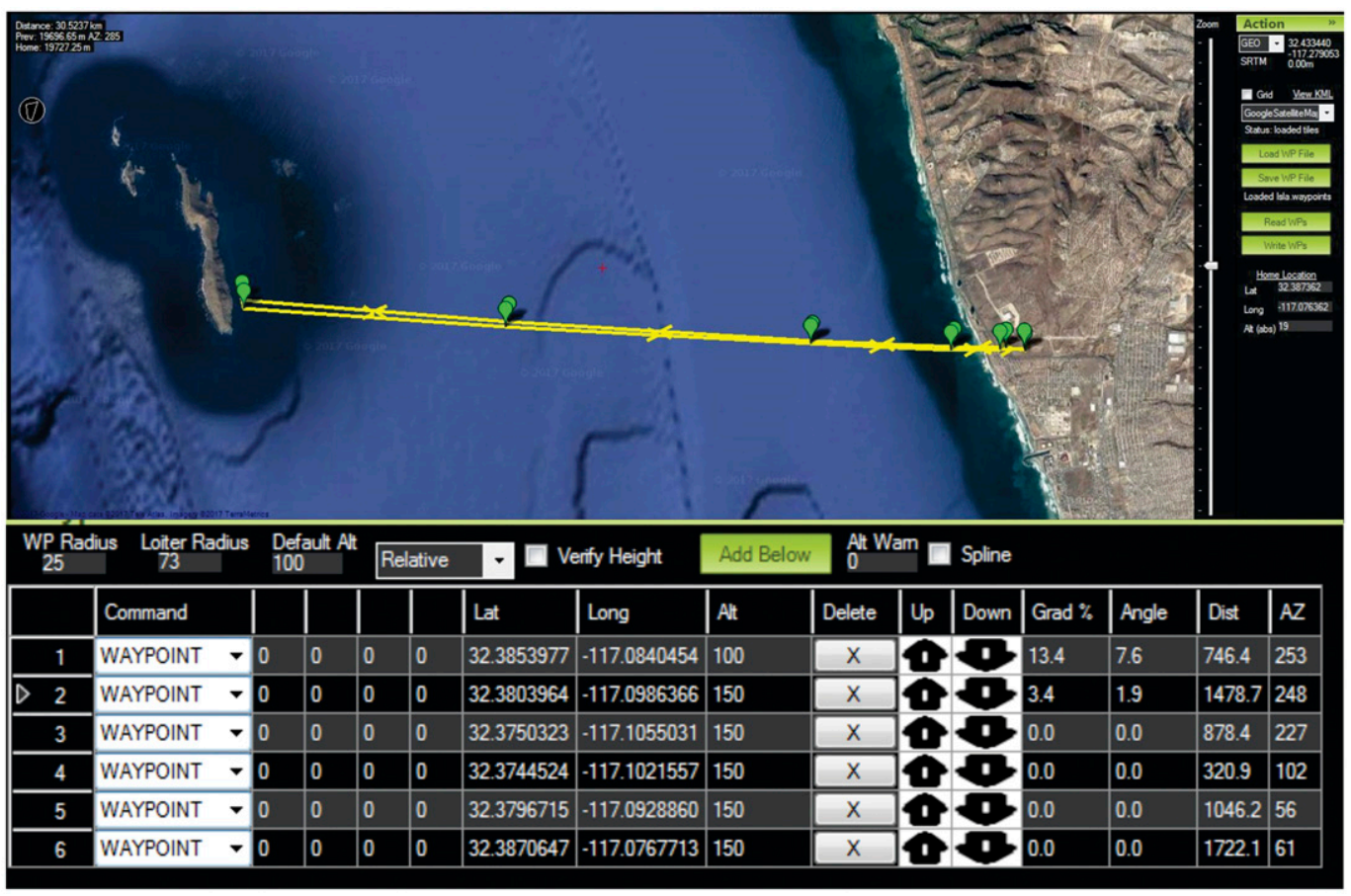

FIG. 3. Example of a typical mission configuration. (top) Map with the preprogrammed positions to release the minidrifters (green marks) and flight track (yellow line). (bottom) Programing tool for the minidrifters release. Two right columns are the distance to the target and the delivery altitude. This mission in particular was a $30-\mathrm{km}$ flight. 


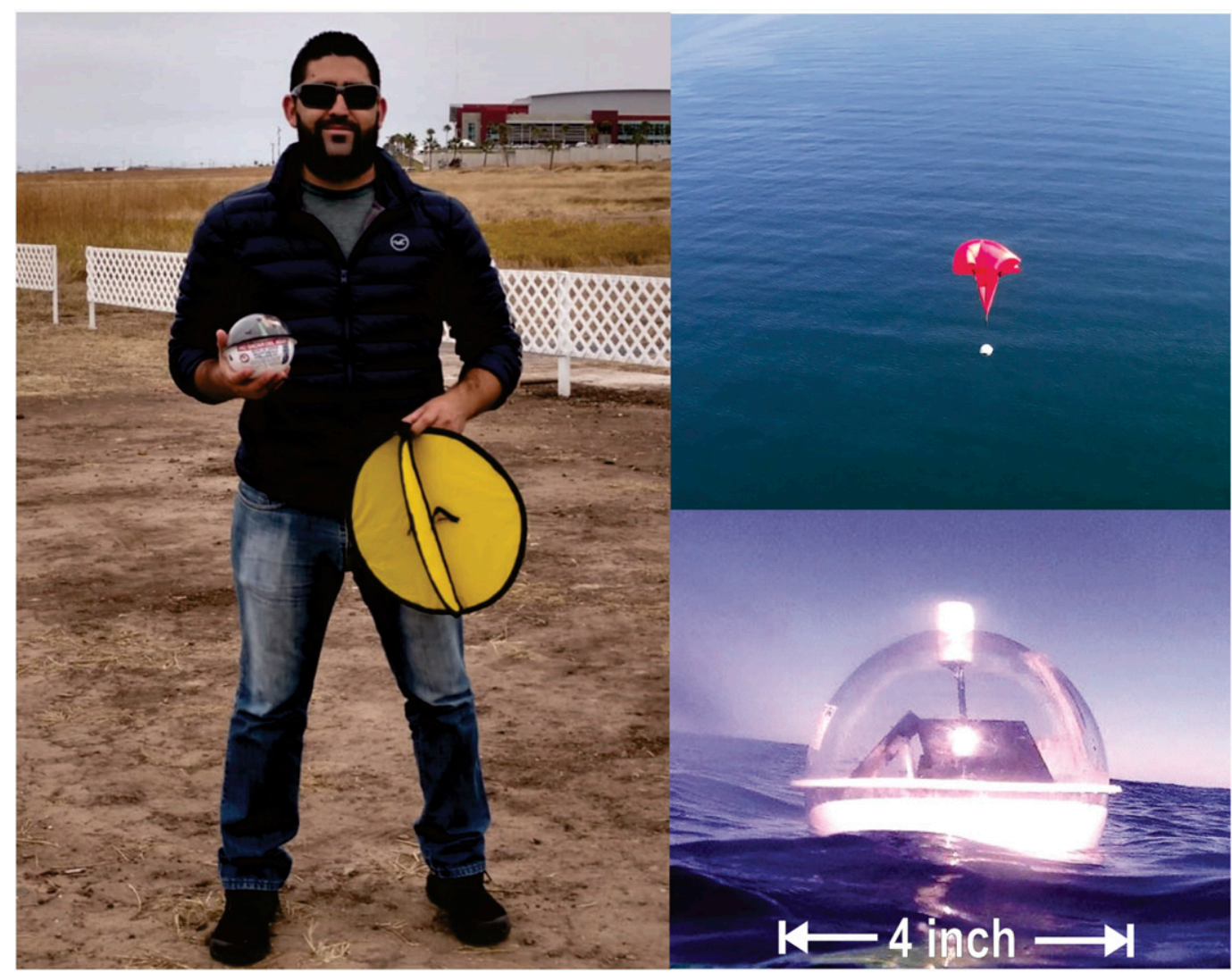

FIG. 4. (left) A minidrifter (right hand of the model) with its underwater drogue (yellow). (top right) A minidrifter with its parachute during one deployment. (bottom right) A minidrifter in the water; its solar panels can be seen in the interior.

allowing us to perform several experiments with different configurations to improve the release system of the ocean drifters.

\section{a. Ocean minidrifters}

Drifters are widely used to measure Lagrangian trajectories and collect environmental data. Some institutions and companies (e.g., Pacificgyre Inc., Lagrangian Drifter Laboratory from University of California at San Diego, Albatros Marine Technologies, among others) develop, use, or sell ocean drifters, mostly buoys, with diameters between 4 and 13 inches $(1 \mathrm{in} .=2.54 \mathrm{~cm})$, and with autonomies from $120 \mathrm{~h}$ up to 2 years. Some drifters can include additional sensors for waves [e.g., WAVY, Directional Wave Spectra (DWS)], temperature, salinity [Surface Velocity Program (SVP), Microstar], and/or atmospheric pressure and wind (e.g., Minimet). Drifter buoys can be very small (4-in. diameter) but with limited autonomy ( $<5$ days), and some are even made of biodegradable materials [e.g., Consortium for Advanced Research on Transport of Hydrocarbon in the Environment (CARTHE); Novelli et al. 2017]. Prices of commercial drifters range from $\$ 1,100$ to $\$ 5,000$ (U.S. dollars), not including the cost of additional sensors and satellite telemetry.

For this study, we used custom made ocean minidrifters developed by the Radio Oceanography Laboratory of the
Autonomous University of Baja California (UABC; for its Spanish acronym), based on a printed circuit board (PCB) named DORIS. These drifters were specially designed to be as small as possible and tough enough to be released at 500-m altitudes from a flying UAV. The drifters were equipped with GPS [Wide Area Augmentation System (WAAS) enabled-accuracy of less than $3 \mathrm{~m} 95 \%$ of the time], digital temperature sensors of 12 bits with accuracy of $0.1^{\circ} \mathrm{C}$, and two telemetry modules [Iridium-satellite; cellular-Global System for Mobile Communications (GSM)]; the cost of the complete drifter was relatively low $[<\$ 800$ (U.S. dollars)]. The custom software to control the PCB was programmed to be "intelligent" and, therefore, selects the telemetry module depending on the geographical position; it uses the cellular network GSM to transmit near the coast (less than $10 \mathrm{~km}$ offshore) for a negligible cost, whereas far into the open ocean, it uses satellite (Iridium) telemetry for global coverage, which reduces the telemetry costs of the operation $\left[<\$ 2\right.$ (U.S. dollars) month $^{-1}$ when operating in GSM]. The drifters can be programmed to define the time interval of measurements (from $5 \mathrm{~min}$ to $24 \mathrm{~h}$ ) and the drive where measurement will be stored. Measurements can be stored locally in an SD card, or remotely at an online server (or "cloud") for real-time display of its trajectory. When using an SD card, it is possible to set higher sampling rates 

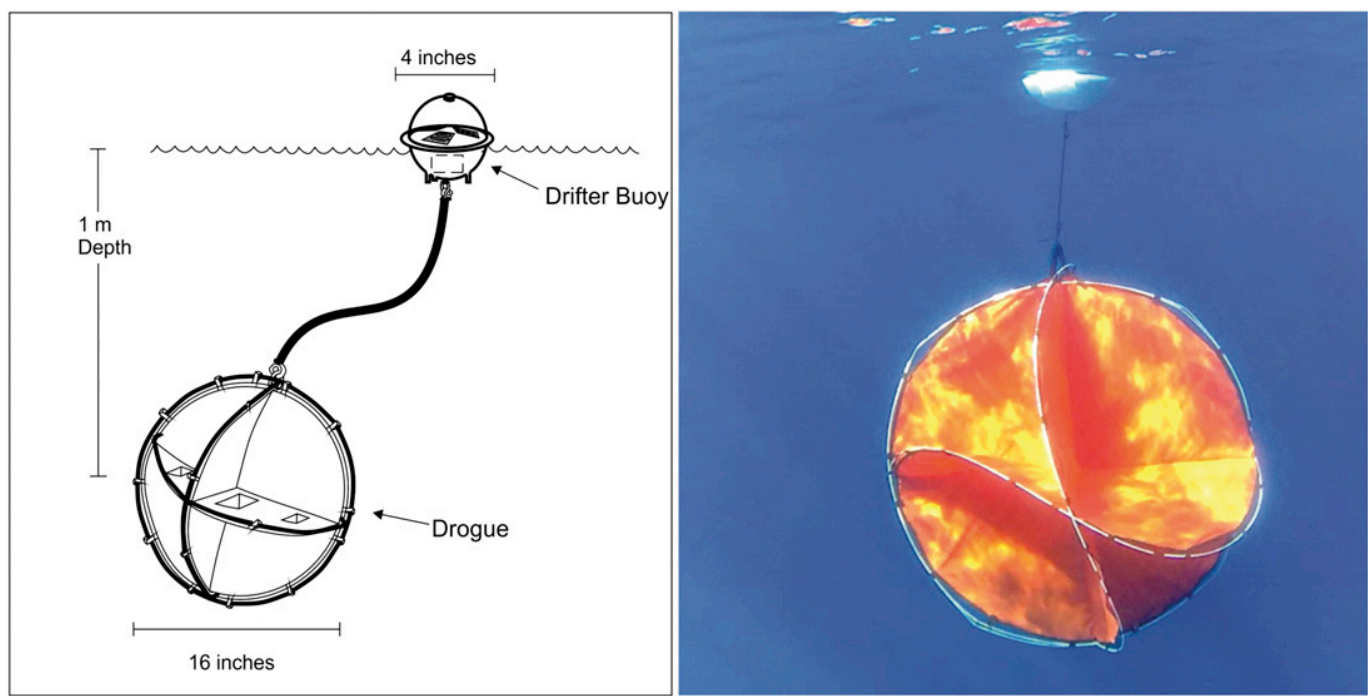

FIG. 5. (left) A sketch of minidrifter with its drogue to ensure direct current influence. (right) A real photograph of the drifter-drogue system.

$(1-10 \mathrm{~Hz})$ for the surf zone and to measure rip currents and stokes drift.

Their compact ( 4 in., roughly the size of an orange) and lightweight (450 g) design (Fig. 4) allows them to be released quickly from a boat or a UAV. Their body is composed of polylactic acid or polylactide (PLA), which is a thermoplastic polymer composed of lactic acid (environmentally friendly), and are equipped with photocells that provide the sensors and telemetry modules with autonomy for several weeks or even months, depending on sampling period and sun-clouds conditions. The drifter has a subsurface drogue (Fig. 5) made of a bamboo textile cloth which is biodegradable and marine-life friendly. The drag area ratio of the drogue was 40:1, which results in $<0.6 \mathrm{~cm} \mathrm{~s}^{-1}$ of downwind slip in $10 \mathrm{~ms}^{-1}$ winds (Niiler et al. 1995). Once in the water, the drifter sends data (in real time) to an online server (https://oorco.ens.uabc.mx) where an automatic running software perform the first quality control, removes bad flagged values, and plots the results to show a first insight of the data.

\section{b. Release system}

A few companies (e.g., Zipline Inc. and Wing Aviation LLC) use custom UAVs to transport products, mostly focusing on transporting medications and surgical materials to areas that are difficult to access. They use fixed-wing platforms with a compartment bay located in the fuselage, just under the center of gravity, and the release system is equipped with servocontrolled doors; however, these are limited to one release per flight. Here we present a UAV capable of releasing up to six ocean minidrifters in a single flight.

To release the drifters without damaging the UAV or the drifters during the free-fall, a release tunnel was built into the UAV structure (Fig. 6). The drifters were loaded into the tunnel and locked with a servo that opens when the UAV reaches the preprogrammed point. The drifter has a parachute that opens as soon as the drifter leaves the UAV (see top-right panel of Fig. 4) to reduce the speed during the free fall and to avoid damage when it hits the water surface. The drifter has its subsurface drogue secured with paper tape that opens when the drifter enters the water (simply by breaking the tape when wet). This system was the product of several field tests; the distance from the tunnel to the propeller was carefully selected to avoid the parachute getting tangled or causing damage to the UAV. The size of the parachute guarantees that the drifter will be deposited smoothly in the water without damaging its internal components. It is worth mentioning that the parachute is made of organic paper, so it degrades when it gets wet and disintegrates, leaving only the drifter and its subsurface drogue on the water.

\section{Results}

More than 40 flights were performed between January 2017 and October 2019, achieving flights with ranges of 5-30 km and with different payloads. All flights were performed in Baja California, Mexico, releasing about 30 minidrifters during the trials. In the following results we evaluate the integrity of the drifter after deployment, the maximum range of the delivery, the capability of simultaneous deliveries in a single flight, and the precision of the delivery.

In this work, we configured the DORIS minidrifters with sampling rates of $1 \mathrm{~h}$ for long-lasting deployments and of $10 \mathrm{~min}$ to capture small-scale variability, sending data to our online server through Iridium and the GSM network, respectively.

Figure 7 shows the $\sim 3$-month trajectory of a minidrifter sampling every hour. The drifter was released $\sim 6 \mathrm{~km}$ offshore at 200-m altitude. After its deployment, the drifter sent data of its position through GSM for approximately 5 days, then the drifter lost communication through GSM and started sending data via Iridium, resulting in more than 2000 messages [short burst data (SBD)]. The GPS on board the drifter returned its position successfully, showing the well-known southward drift of the Baja California coast (Durazo 2015). Surface temperature 

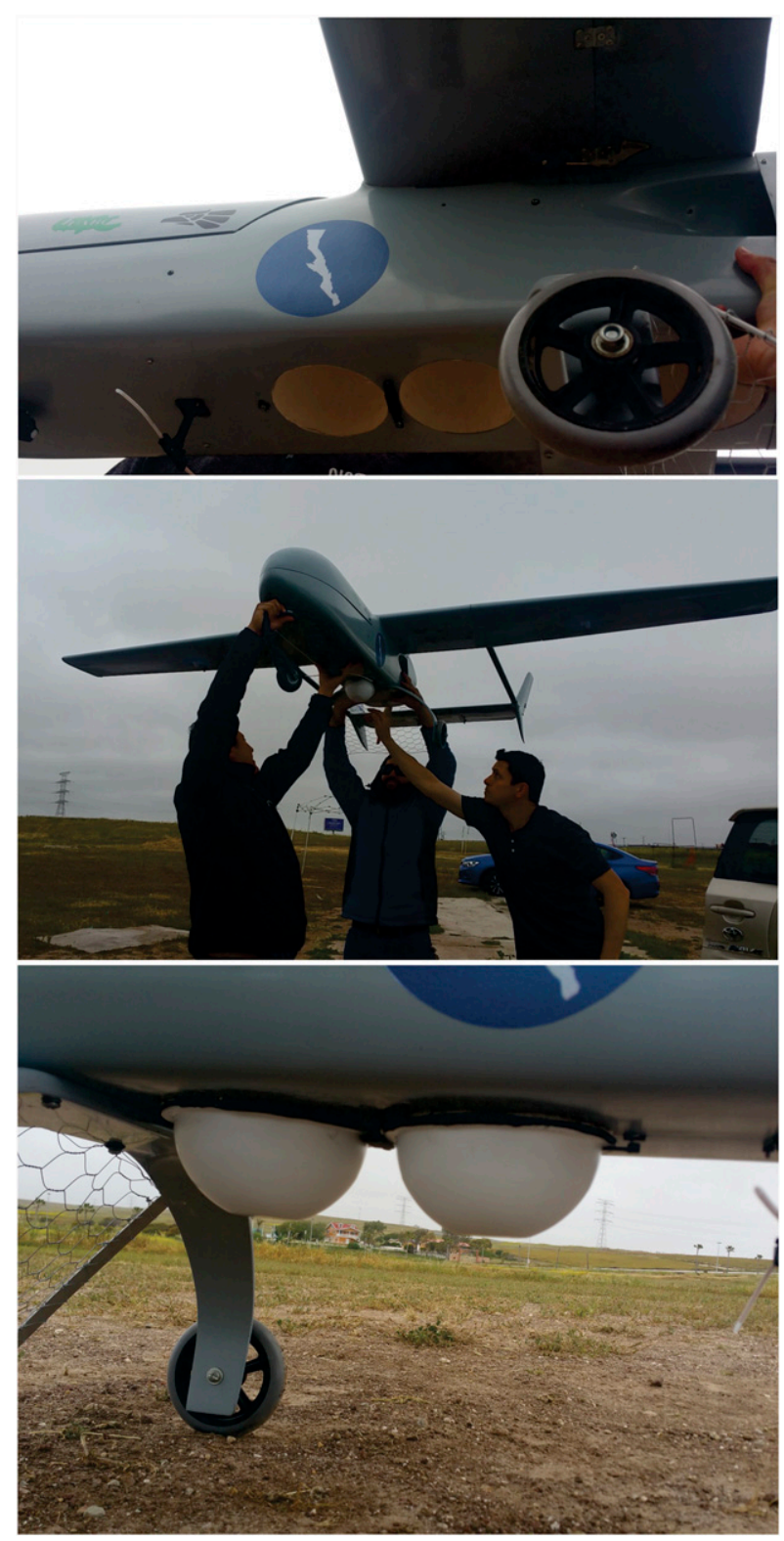

FIG. 6. (top) The empty release tunnels. (middle) The minidrifters being load into the release tunnels. (bottom) The tunnels with two minidrifters ready to be released.

was recorded simultaneously with the onboard sensor, showing cooler waters at the north and relatively warmer waters as it drifted southward, which was also consistent with the regional oceanography in the area.

The bottom panel of Fig. 7 shows that batteries were successfully charged by the solar panels, showing a time series of the voltage with a negligible trend over the $\sim 3$ months of measurements. A few days before 21 November cloudy conditions caused a slight discharge of the batteries; this allowed us to confirm the robustness of the battery-solar panel array, which was able to manage cloudy conditions by recovering the battery level to safe values.
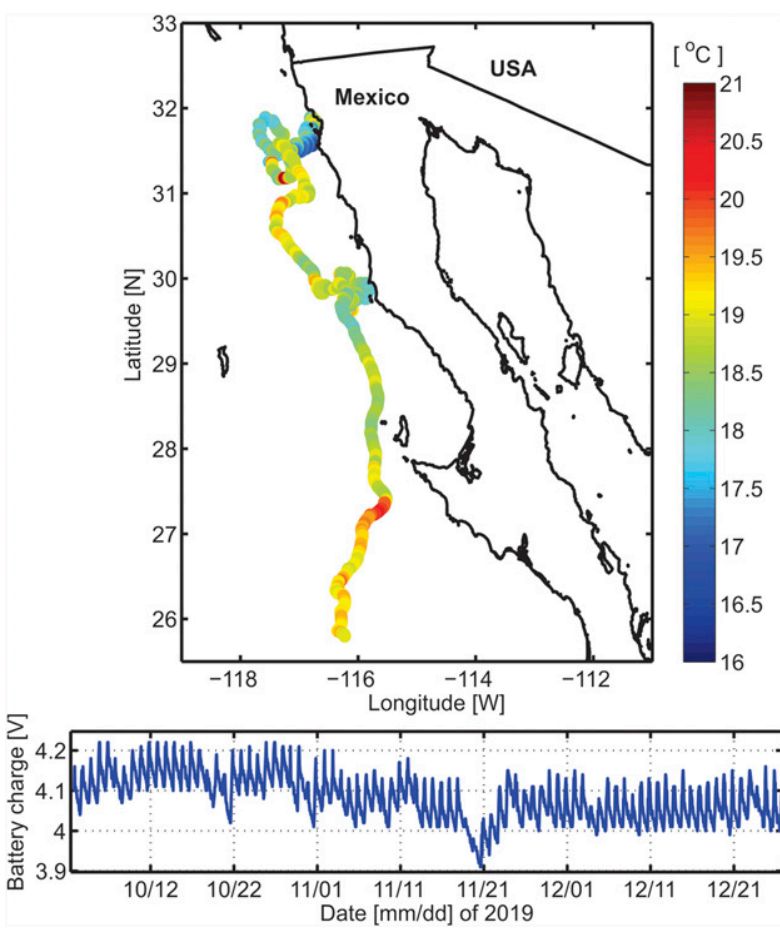

FIG. 7. (top) A 3-month trajectory performed by one of our minidrifters equipped with GPS (WAAS enabled) and temperature (colors of the trajectory) logger. (bottom) The battery voltage during the entire mission.

Figure 8 shows data from six drifters programmed to take measurements every $10 \mathrm{~min}$ and loaded into the UAV to assess the capacity of the UAV to perform simultaneous deliveries beyond $10 \mathrm{~km}$ offshore in a single flight. The flight path was programmed to be perpendicular to the coast and to release the drifters every $\sim 2 \mathrm{~km}$, up to $12 \mathrm{~km}$ offshore, and at $\sim 500 \mathrm{~m}$ of altitude. The buoys drifted toward the south (consistent with the typical currents in the area) and sent real-time data during $\sim 5$ days. The trajectories shown in Fig. 8a covered only one day of measurements in order to compare them with a sea surface temperature (SST)-satellite derived map [obtained from the EU Copernicus Marine Environment Monitoring Service (CMEMS) Operational Sea Surface Temperature and Sea Ice Analysis (OSTIA) and described in Donlon et al. (2012)]. Figure $8 \mathrm{~b}$ shows the temperatures recorded by the drifters interpolated over a Cartesian grid, which is in a good agreement with satellite derived SST (Fig. 8c). Both (Figs. 8b and $8 \mathrm{c}$ ) confirm the capability of the minidrifters to measure additional ocean parameters other than trajectories, which demonstrates the potential of the tool presented here.

To seek for longer endurance of the UAV and therefore obtain farther deliveries, we conducted a battery discharge analysis during six flights with distances from 5 to $30 \mathrm{~km}$ at $\sim 5-\mathrm{km}$ intervals. Figure 9 shows the battery discharge as function of the distance traveled. In addition, Table 1 shows these results with the addition of UAV speed, flight time, and wind speed conditions. The $\sim 5$-km flights, which maintained a speed of $\sim 80 \mathrm{~km} \mathrm{~h}^{-1}$ for $\sim 8 \mathrm{~min}$, showed battery consumption 

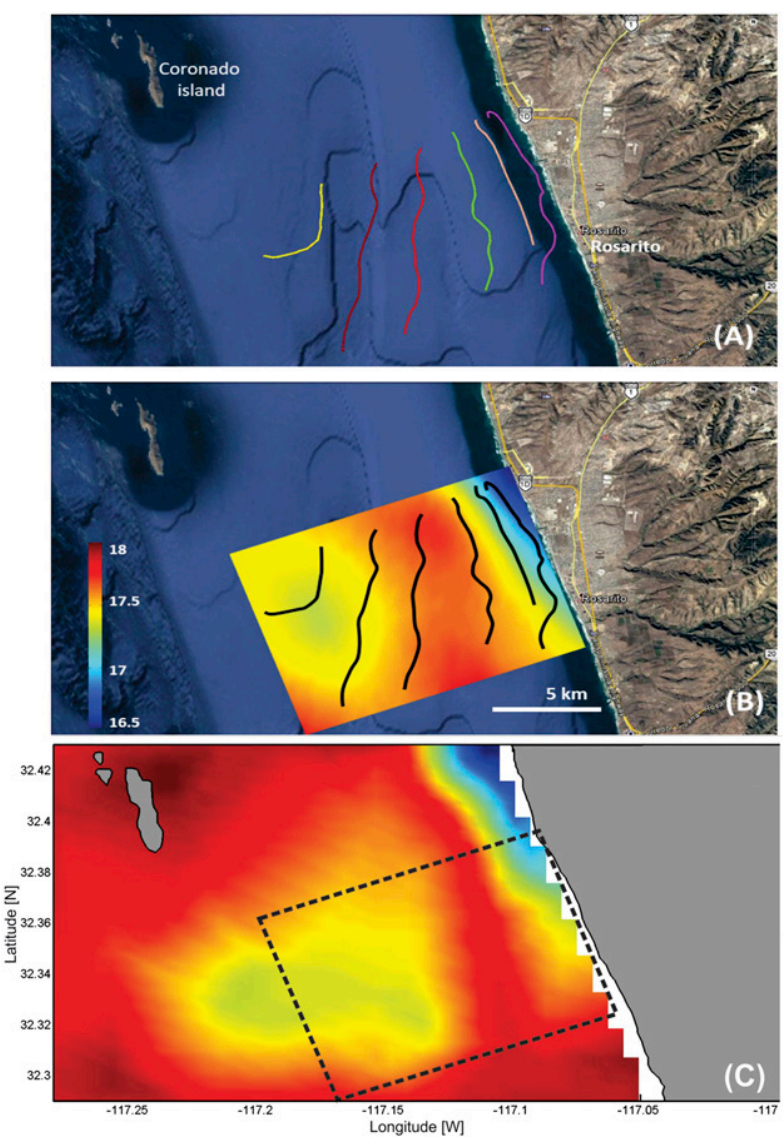

FIG. 8. Data from six minidrifters released at $500 \mathrm{~m}$ of altitude. (a) The drift trajectories (color lines) toward the south. First instrument was released about $2 \mathrm{~km}$ offshore, while the farthest one was about $12 \mathrm{~km}$ offshore. (b) The SST composed by interpolating the temperature values recorded for each drifter over a Cartesian grid. (c) The satellite SST obtained from Copernicus Marine Environment Monitoring Service. The temperature color scale is the same for (b) and (c).

of $15 \%$, whereas the $\sim 30-\mathrm{km}$ flights showed a consumption of about $70 \%$ at the same cruise speed; this flight was completed in about $31 \mathrm{~min}$. These results showed a linear discharge and gave us confidence in the battery array, and therefore in the safety of the flight. We used these results to define the optimum

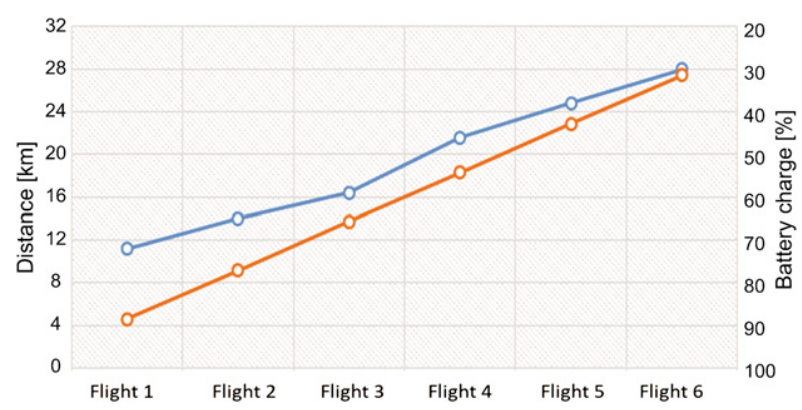

FIG. 9. Battery charge (blue line) and traveled distance (red line) vs flight trials.
TABLE 1. Values of battery discharge (\%), traveled distance $(\mathrm{km})$, elapsed time $(\mathrm{min})$, wind speed $(\mathrm{kt})$, aircraft speed $\left(\mathrm{km} \mathrm{h}^{-1}\right)$, and payload $(\mathrm{g})$ during six flights performed to evaluate the behavior of the batteries.

\begin{tabular}{lcccccc}
\hline \hline & \multicolumn{7}{c}{ Flight } \\
\cline { 2 - 7 } & 1 & 2 & 3 & 4 & 5 & 6 \\
\hline Battery discharge (\%) & 28 & 35 & 41 & 54 & 61 & 70 \\
Traveled distance (km) & 5 & 10 & 15 & 20 & 25 & 30 \\
Elapsed time (min) & 8 & 12 & 15 & 19 & 23 & 31 \\
Wind speed (kt) & 5.5 & 6 & 5 & 5.2 & 6.1 & 4.9 \\
Aircraft speed (km h & -1 ) & \multicolumn{7}{c}{$\sim 80$} \\
Payload (g) & \multicolumn{7}{c}{2700} \\
\hline
\end{tabular}

cruise speed, finding the correct compromise between the discharge, payload, and traveled distance. Note that the payload for these tests was $\sim 2.7 \mathrm{~kg}$ (six minidrifters).

For flights beyond $10 \mathrm{~km}$ offshore, a compromise between the height of the ground station antenna and the aircraft altitude was made to keep the strength of the telemetry link. Raising the ground telemetry antenna was not a practical solution due to the logistics of installing antennas at a 60-80-m height. Hence, the altitude of the aircraft was increased, keeping an altitude above $400 \mathrm{~m}$. However, for drifter deliveries between 10 and $30 \mathrm{~km}$ offshore (performed at $\sim 400 \mathrm{~m}$ of altitude), the distance between the release point (in the air) and the first data in the water was unknown and necessary to evaluate to estimate the accuracy of the delivery. Therefore, three tests were performed, increasing the distance to shore (DTS) during each one and, therefore, the altitude. Figure 10 shows a single release performed at about 3-km DTS and $\sim 70$-m altitude. The blue dashed line is the UAV trajectory and the red line and the pink star are the minidrifter trajectory once in the water and the release point, respectively. The horizontal distance between the release point in the air and the first data taken by the minidrifter in the water was about $167 \mathrm{~m}$.

Figure 11 shows a release performed at about 6-km DTS and $\sim 150$-m altitude. The horizontal distance between the release in the air and the first data in the water was $\sim 172 \mathrm{~m}$. Finally, the farthest drifter release tested is shown in Fig. 12. This flight was

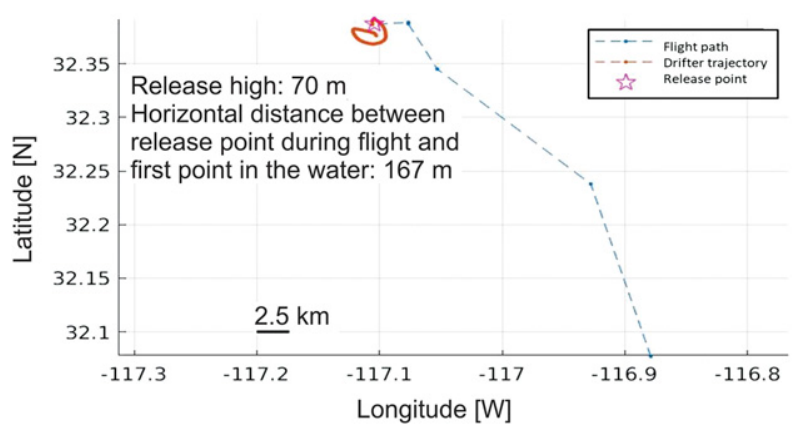

FIG. 10. UAV trajectory (blue dashed line) during a 3-km mission and minidrifter trajectory (red dotted line) after being released at $70 \mathrm{~m}$ above sea level. Pink star shows the release coordinates. 


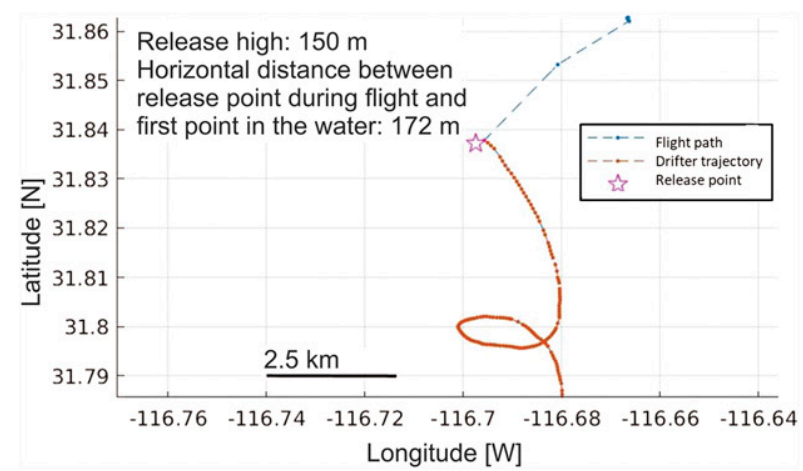

FIG. 11. UAV trajectory (blue dashed line) during a 6-km mission and minidrifter trajectory (red dotted line) after being released at $150 \mathrm{~m}$ above sea level. Pink star shows the release coordinates.

about $30-\mathrm{km}$ DTS with a release altitude of $\sim 418 \mathrm{~m}$, and again the horizontal distance between the release point and the first data at the water was $\sim 160 \mathrm{~m}$. Note that the total traveled distance of this flight was about $60 \mathrm{~km}$ (round trip) performed in about $1 \mathrm{~h}$.

This analysis shows that for the three experiments (performed under moderate wind conditions of $<10 \mathrm{kt}$ ) the distance between the release point in the air and the first data taken in the water were less than $180 \mathrm{~m}$, giving us an estimate of the precision of our shot.

\section{Conclusions}

This work shows an off-the-shelf, open-source tool capable of releasing ocean minidrifters for oceanographic research purposes or quick response in oil spills, red tides, search and rescue operations, or any ocean distress phenomena that require rapid estimations of ocean currents (drift trajectories) and water parameters (e.g., temperature). The tool consists of a modified UAV with autonomy of $\sim 1 \mathrm{~h}$ and a payload of $\sim 5 \mathrm{~kg}$, which was able to transport up to six ocean minidrifters beyond $10 \mathrm{~km}$ offshore. The missions were programmed using open-source software that allows the user to define missions and release points for minidrifters. The autopilot (off the shelf) can perform the preprogrammed mission with minimum human assistance and high accuracy. Minidrifters were equipped with a parachute and a drogue to ensure free-fall safety and force drift by currents, respectively. The built-in release tunnel in the UAV was fitted correctly to avoid collision between minidrifters and any part of the UAV when leaving the aircraft.

Once in the water, the drifters were able to measure ocean temperature and its position with high precision $\left(\sim 0.1^{\circ} \mathrm{C}\right.$ and -3-6 m, respectively). Preprogramed drifters with a 1-h sampling rate recorded 3 months of data, whereas drifters with faster sampling rates of $10 \mathrm{~min}$ recorded 1 week of data. Hence, its autonomy shows the capacity to measure small-scale variability near the shore $(<10 \mathrm{~km})$, with negligible cost [less than $\$ 2$ (U.S. dollars) month ${ }^{-1}$ using GSM for real-time telemetry], and more regional-scale variability several kilometers beyond $10 \mathrm{~km}$ offshore [sampling rate of $1 \mathrm{~h}$ using Iridium telemetry cost about $\$ 30$ (U.S. dollars) month -1 ]. Sea surface temperature was

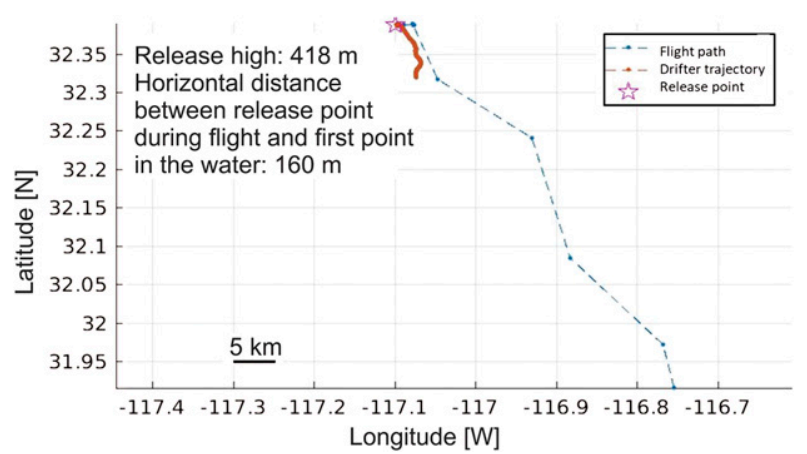

FIG. 12. UAV trajectory (blue dashed line) during a 30-km mission and minidrifter trajectory (red dotted line) after being released at $400 \mathrm{~m}$ above sea level. Pink star shows the release coordinates.

successfully recovered from the temperature sensor, showing a generally good agreement with the satellite products.

The results of this work is a low-cost open-source operational UAV that releases oceanographic instrumentation (up to six minidrifters) beyond $10 \mathrm{~km}$ offshore with an unprecedented release time of less than $15 \mathrm{~min}$, providing useful oceanographic information in real time.

Acknowledgments. This project was founded by the SENERCONACyT Project 201441 and Subproject 10999. DORIS is a trademark of the Autonomous University of Baja California. Pixhawk is a trademark of Lorenz Meier.

\section{REFERENCES}

De Sousa, J. B., P. McGuillivary, J. Vicente, M. Nunes Bento, J. A. P. Morgado, M. Madruga Matos, R. A. Gomes Bencatel, and P. Mónica de Oliveira, 2015: Unmanned aircraft systems for maritime operations. Handbook of Unmanned Aerial Vehicles, K. Valavanis and G. Vachtsevanos, Eds., Springer, 2787-2811, https://doi.org/10.1007/978-90-481-9707-1_75.

Díaz Méndez, G. M., M. C. Haller, B. Raubenheimer, S. Elgar, and D. A. Honegger, 2015: Radar remote sensing estimates of waves and wave forcing at a tidal inlet. J. Atmos. Oceanic Technol., 32, 842-854, https://doi.org/10.1175/JTECH-D-14-00215.1.

Dohan, K., 2017: Ocean surface currents from satellite data. J. Geophys. Res. Oceans, 122, 2647-2651, https://doi.org/ 10.1002/2017JC012961.

_ , and N. Maximenko, 2010: Monitoring ocean currents with satellite sensors. Oceanography, 23 (4), 94-103, https://doi.org/ 10.5670/oceanog.2010.08.

Donlon, C. J., M. Martin, J. Stark, J. Roberts-Jones, E. Fiedler, and W. Wimmer, 2012: The Operational Sea Surface Temperature and Sea Ice Analysis (OSTIA) system. Remote Sens. Environ., 116, 140-158, https://doi.org/10.1016/j.rse.2010.10.017.

Durazo, R., 2015: Seasonality of the transitional region of the California Current system off Baja California. J. Geophys. Res. Oceans, 120, 1173-1196, https://doi.org/10.1002/2014JC010405.

Fingas, M., and C. E. Brown, 2011: Oil spill remote sensing: A review. Oil Spill Science and Technology, M. Fingas, Ed., Gulf Publishing Company, 111-169.

Grodsky, S. A., R. Lumpkin, and J. A. Carton, 2011: Spurious trends in global surface drifter currents. Geophys. Res. Lett., 38, L10606, https://doi.org/10.1029/2011GL047393. 
Hu, C., and Coauthors, 2016: Sargassum watch warns of incoming seaweed. Eos, Trans. Amer. Geophys. Union, 97, https:// doi.org/10.1029/2016EO058355.

Kaplan D. M., J. Largier and L. W. Botsford, 2005: HF radar observations of surface circulation off Bodega Bay (Northern California, USA). J. Geophys. Res., 110, C10020, https:// doi.org/10.1029/2005JC002959.

Klimkowska, A., I. Lee, and K. Choi, 2016: Possibilities of UAS for maritime monitoring. Int. Arch. Photogramm. Remote Sens. Spatial Inf. Sci., 41, 885-891, https://doi.org/10.5194/isprsarchives-XLI-B1-885-2016.

Mateos, E., S. G. Marinone Moschetto, and M. F. Lavín Peregrina, 2013: Numerical modeling of the coastal circulation off northern Baja California and southern California. Cont. Shelf Res., 58, 50-66, https://doi.org/ 10.1016/j.csr.2013.02.008.

Miron, P., F. J. Beron Vera, H. J. Olascoaga, G. Froyland, J. Sheinbaum Pardo, and P. Pérez Brunius, 2019: Lagrangian geography of the deep Gulf of Mexico. J. Phys. Oceanogr., 49, 269-290, https://doi.org/10.1175/JPO-D-18-0073.1.

Niiler, P. P., A. Sybrandy, K. Bi, P. Poulain, and D. Bitterman, 1995: Measurements of the water-following capability of holey-sock and TRISTAR drifters. Deep-Sea Res. I, 42, 1951-1964, https:// doi.org/10.1016/0967-0637(95)00076-3.

Novelli, G., C. M. Guigand, C. Cousin, E. H. Ryan, N. J. M. Laxague, H. Dai, B. K. Haus, and T. M. Özgökmen, 2017: A biodegradable surface drifter for ocean sampling on a massive scale. J. Atmos. Oceanic Technol., 34, 2509-2532, https:// doi.org/10.1175/JTECH-D-17-0055.1.

Paduan, J. D., and L. Washburn, 2013: High-frequency radar observations of ocean surface currents. Annu. Rev. Mar. Sci., 5, 115-136, https://doi.org/10.1146/annurev-marine121211-172315.
Reineman, B. D., L. Lenain, D. Castel, and W. K. Melville, 2009: A portable airborne scanning lidar system for ocean and coastal applications. J. Atmos. Oceanic Technol., 26, 2626-2641, https://doi.org/10.1175/2009JTECHO703.1.

,$- \ldots$, and W. K. Melville, 2016: The use of ship-launched fixed-wing UAVs for measuring the marine atmospheric boundary layer and ocean surface processes. J. Atmos. Oceanic Technol., 33, 2029-2052, https://doi.org/10.1175/ JTECH-D-15-0019.1.

Serra-Sogas, N., P. D. O'Hara, R. Canessa, P. Keller, and R. Pelot, 2008: Visualization of spatial patterns and temporal trends for aerial surveillance of illegal oil discharges in western Canadian marine waters. Mar. Pollut. Bull., 56, 825-833, https://doi.org/ 10.1016/j.marpolbul.2008.02.005.

Skrzypietz, T., 2012: Unmanned aircraft systems for civilian mission. Brandenburg Institute for Society and Security Policy Paper 1, 28 pp.

Trasviña-Moreno, C. A., R. Blasco, A. Marco, R. Casas, and A. Trasviña-Castro, 2017: Unmanned aerial vehicle based wireless sensor network for marine-coastal environment monitoring. Sensors, 17, 460, https://doi.org/10.3390/s17030460.

Valente, J., D. Sanz, A. Barrientos, J. del Cerro, A. Ribeiro, and C. Rossi, 2011: Air-ground wireless sensor network for crop monitoring. Sensors, 11, 6088-6108, https://doi.org/10.3390/ s110606088.

Ventura, D., A. Bonifazi, M. F. Gravina, and G. D. Ardizzone, 2017: Unmanned aerial systems (UASs) for environmental monitoring: A review with applications in coastal habitats. Aerial Robots-Aerodynamics, Control and Applications, IntechOpen, https://doi.org/10.5772/intechopen.69598.

Verfuss, U. K., and Coauthors, 2019: A review of unmanned vehicles for the detection and monitoring of marine fauna. Mar. Pollut. Bull., 140, 17-29, https://doi.org/10.1016/j.marpolbul.2019.01.009. 